\title{
FINITE ELEMENT ANALYSIS OF THE FLEXURAL BEHAVIOR OF CORRODED RC BEAMS STRENGTHENED BY CFRP SHEETS
}

\author{
Hoai Anh Tran ${ }^{1,2}$, "Ngoc Tan Nguyen ${ }^{1}$, Trung Kien Nguyen ${ }^{1}$, Hoang Giang Nguyen ${ }^{1}$ \\ ${ }^{1}$ Faculty of Building and Industrial Construction, Hanoi University of Civil Engineering, Vietnam; ${ }^{2}$ The South \\ Agency, Ministry of Construction, Vietnam.
}

*Corresponding Author, Received: 11 Nov. 2021, Revised: 01 Dec. 2021, Accepted: 18 Dec. 2021

\begin{abstract}
In the present study, a series of numerical modeling is performed in order to investigate the structural behavior of corroded reinforced concrete beams externally strengthened to tension area with CFRP (Carbon Fiber Reinforced Polymer) with the aid of the finite element method adopted. A three-dimensional model employing the nonlinear characteristics of materials (e.g. elasto-plastic material model of steel reinforcement and damaged concrete model due to corrosion, bond stress-slip behavior between steel and concrete in good and deteriorated conditions) is created and validated. The numerical results obtained from the finite element analysis (FEA) are compared with the experimental results for six RC beams with different degrees of corrosion. The accuracy of the finite element models is based on comparison with the experimental curves of load-deflection. Results obtained from FEA showed a good correlation between the predicted residual flexural capacity and experimental results. The parametric study is then conducted to examine the capability of the FE model on assessing the structural behavior of the FRP-strengthened corroded RC beams in various strengthening conditions.
\end{abstract}

Keywords: Corroded beams, Steel corrosion, Carbon Fiber Reinforced Polymer, Flexural strengthening, Finite element modeling.

\section{INTRODUCTION}

Steel corrosion is one of the main causes of deterioration in reinforced concrete (RC) structures. Many research works suggest that high durability requirements are not always achieved in practice due to corrosion of reinforcement [1]. The principal effects of corrosion on structural elements are loss of reinforcement cross-section and altering its mechanical properties, owing to the volumetric expansion compared to the base reinforcing bars, the generation of internal pressure induces splitting stresses. This stress-induced can lead to cracking and the reduction of compressive strength of the concrete cover when it reaches the tensile capacity of the concrete. As the splitting cracks develop, the confinement action of the concrete is rapidly decreased thereby reducing the bond strength at the interface between steel and concrete [2-4]. Therefore, deteriorated structures should be repaired to ensure proper functioning, to extend their service life, and to accommodate changes in increased loads.

As such, one alternative way to rehabilitate the deteriorated structures is to utilize fiber-reinforced polymer (FRP) composite materials, which are currently viewed by structural engineers as new and highly promising materials in the industry [1]. Advantages of FRP materials include a high strengthto-weight which is more applicable in confined space, excellent corrosion resistance, and high tensile strength. Regarding the application of FRP composites on corroded structures, several applications involve externally bonded composite fabrics, are significant in compressive, shear and flexural performances have been obtained. The overall performance of the RC beam under service load is slightly improved and the load-carrying capacity is remarkably increased when strengthening FRP sheets are used [5-8].

Furthermore, the finite element method (FEM) is extremely effective to solve the engineering problems especially structures having complex boundary conditions. It has been used widely for the structural analysis of reinforced concrete structures including FRP strengthened RC structures. Many previous numerical research works had demonstrated good agreement with experimental results [9-11].

However, from the literature, less attention has been paid to study the structural performance of corroded RC beams strengthened by FRP composites employing FEM. In this paper, the numerical results obtained from the FEA are compared with the experimental results for two non-corroded RC beams, two corroded RC beams and two corroded CFRP strengthened RC beams. The failure modes of the strengthened corroded beams are governed mainly by the bond between the CFRP sheet and concrete cover because it is the means for the transfer of stresses to develop composite action. The numerical analysis is then broadened, a parametric study is conducted considering the number of CFRP layers and the length of the CFRP sheets. Finally, the FEA confirmed the suitability of the model to predict the mechanical behavior of corroded RC members 
strengthened in flexure with the CFRP material considering many variables.

\section{NUMERICAL MODELING}

A three-dimensional nonlinear model is developed using DIANA FEA software. In analyses, the smeared crack concept was used with a rotating crack model based on total strain. The constitutive models of materials with element types applied in geometric modeling are used to develop the FE model with the validation from an experimental study with three sets of tested RC beams [11].

\subsection{Finite Element Model (FEM)}

In this study, the mesh size of concrete elements was investigated. Furthermore, the average mesh size corresponding to three times the diameter of maximum aggregates has been recommended [12]. The minimum mesh size is usually deemed the maximum size of coarse aggregates due to the heterogeneity of the concrete material. The threedimensional (3D) analysis can be calculated with accuracy employing an acceptably large mesh size [13].

Hence, the load-deflection curves responded from FE analysis of non-corroded beams with different mesh sizes ranging from 20 to $100 \mathrm{~mm}$ were performed and illustrated in Fig. 1. Based on the computational time and accuracy of the obtained results, the mesh size of $50 \times 50 \times 50 \mathrm{~mm}$ has been selected for numerical modeling as in Fig. 2.

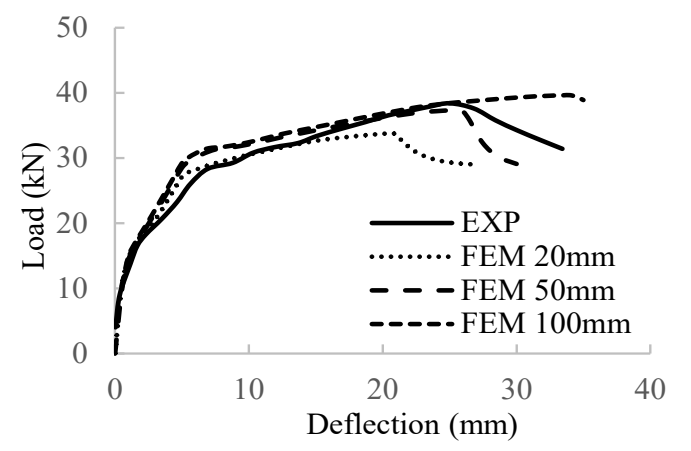

Fig. 1 Convergence study

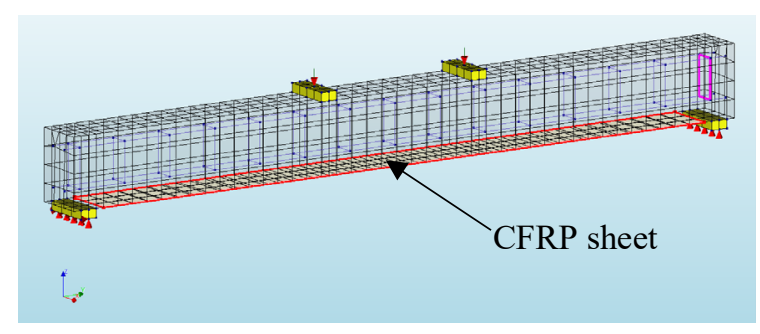

Fig. 2 Mesh discretization of the beam, CFRP sheet and the load, support conditions

\subsubsection{Concrete, steel plates and CFRP sheet}

Three-dimensional CHX60 element, a twentynode isoparametric solid brick element, is employed for the concrete, CFRP laminates, support, and loading steel plates as illustrated in the DIANA FEA library [14]. Steel plates are added at support and loading locations in the finite element models (as in the actual beams) in order to avoid stress concentration problems.

\subsubsection{Steel reinforcements}

In the model of non-corroded RC beam, embedded bar elements are assigned for the longitudinal reinforcement and stirrups. They were embedded in the continuum element and their strains are calculated based on the displacement field of the surrounding continuum element.

When the failure mode is not governed by the bond between steel and concrete, the behavior of structural tested beams can be predicted using the perfect bond assumption. In case, the steel-concrete bond controlled the failure mechanism and structural performance of corroded RC beam as demonstrated in many previous experimental studies, the steel bars are modeled as bond-slip reinforcements. A line-solid interface element is employed to simulate the influence of bond stress-slip behavior.

\subsubsection{Concrete-CFRP interface}

A tie constraint is used to model the interaction between the different materials. The assumption that all materials had a perfect bond to one another is made.

\subsection{Materials Modeling}

\subsubsection{Concrete}

In the adopted rotating crack model, the concrete behavior in tension is described by the stress-strain curve of JSCE tension softening defined by the tensile strength and mode-I tensile fracture energy. The parabolic stress-strain curve in DIANA software is used for compression considering the reduction model due to lateral cracking and stress confinement model [14]. The post-peak response of this curve employing fracture energy and crack bandwidth as recommended [15]. The damaged concrete model due to corrosion was proposed by a reducing stress-strain relationship as suggested in [16].

\subsubsection{Steel reinforcements and steel plates}

The FEM employed linear elastic isotropic material to model steel plates at support and loading positions. An elasto-plastic material with linear strain hardening was assigned to reinforcements. The tangent modulus in the plastic stage is set equal to one-hundredth of the modulus of elasticity. The appearance of pitting corrosion of reinforcements across their lengths has been shown to affect the strength and ductility of corroded reinforcement in 
previous studies [17], [18]. Since it is difficult to incorporate the actual variability of steel corrosion into a numerical model, an alternative method is to model the corroded steel bar over a length employing average cross-section loss.

\subsubsection{CFRP sheet}

Although the CFRP sheet is an orthotropic material that has higher modulus and strength in woven directions than through the thickness directions), it could be modeled as an isotropic material within the plane. This is because the loading on the CFRP sheet is spreading within the sheet plane.

\subsubsection{Damaged steel-concrete interface}

The bond between reinforcements and concrete covering plays a significant role in the mechanical response of the structures attacked by corrosion [2][4]. Moreover, pullout failure often seen in the structure where steel reinforcements embedded in well-confined concrete. Therefore, the bond stressslip curve characterized pullout failure mode as shown in Fig. 3 from CEB-FIP Model Code 1990 [19] is adopted to model the bond between steel and concrete.

$$
\begin{array}{ll}
\tau=\tau_{\max }\left(\frac{s}{s_{1}}\right) \alpha & \text { for } 0 \leq s \leq s_{1} \\
\tau=\tau_{\max } & \text { for } s_{1}<s \leq s_{2} \\
\tau=\left(\tau_{\max }-\tau_{f}\right)\left(\frac{s-s_{2}}{s_{3}-s_{2}}\right) & \text { for } s_{2}<s \leq s_{3} \\
\tau=\tau_{f} & \text { for } s_{3}<s
\end{array}
$$

The bond stresses between the reinforcing bar and concrete can be calculated as a function of the relative displacement (denoted $s$ ) as from Eq. (1) to Eq. (4). Where: $\tau_{\max }$ is the maximum bond strength calculated as $\tau_{\max }=1.25 \sqrt{f_{c}} ; \tau_{f}$ is the residual bond strength $\tau_{f}=0.4 \tau_{\max } ; f_{c}$ is the characteristic value of the uniaxial compressive strength of concrete measured on cylindrical specimens. The parameters used in these equations are defined in CEB-FIP Model Code 1990 [19]. In the numerical study of Tørlen and Horrigmoe [20], in order to characterize the deterioration of bonds in corroded reinforcement, they proposed the deteriorated bond stress-slip curve by reducing maximum bond strength. Moreover, the assumption is made for the unchanged behavior along the deterioration region as illustrated in Fig. 3.

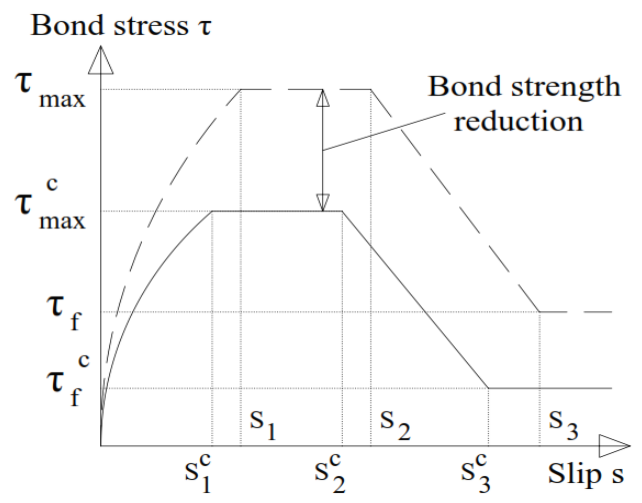

Fig. 3 Bond stress-slip behavior of CEB-FIP 1990 [19] and bond strength reduction model by Tørlen and Horrigmoe [20]

\section{NUMERICAL VALIDATION}

\subsection{Details of Beam Specimens}

The first set comprised the two non-corroded $\mathrm{RC}$ beams named S1-NC and S2-NC that were considered as control beams. The second set has two corroded RC beams named S3-C, S4-C with a corrosion degree of approximately $10 \%$. Lastly, the third set also has two corroded RC beams named S5CFRP, S6-CFRP subjected to a $10 \%$ degree of corrosion, the corroded beams are then sanded and spread with epoxy resin on the surface for covering corrosion cracks before strengthening. All tested beams, which are $2200 \mathrm{~mm}$ long are tested in a fourpoint-bending test as illustrated in Fig. 4. Six beams had the overall depth, the width of $200 \mathrm{~mm}, 150 \mathrm{~mm}$, respectively. Each beam was reinforced in tension and compression with two $\phi 12 \mathrm{~mm}$ longitudinal steel bars, whilst using $\phi 6 \mathrm{~mm}$ stirrups with a spacing of $150 \mathrm{~mm}$. The thickness of a single CFRP layer provided by the manufacturer was $0.111 \mathrm{~mm}$, while the sheet width and length are $150 \mathrm{~mm}$ and $2000 \mathrm{~mm}$, respectively [11].

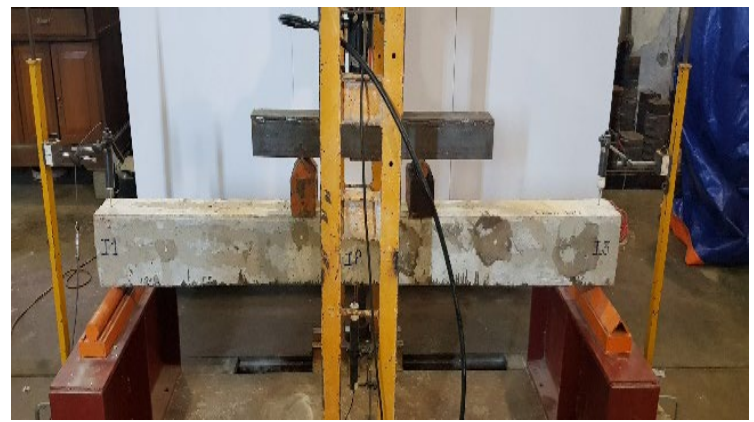

Fig. 4 Four-point bending test on a typical beam specimen 
The compression test of cubic specimens of $150 \mathrm{~mm}$ obtained the average 28-day concrete compressive strength of $40.9 \mathrm{MPa}$ with a coefficient of variation of $1.6 \%$ from the average value. The tensile strength and elastic modulus of the CFRP sheet were $3400 \mathrm{MPa}$ and $245000 \mathrm{MPa}$, respectively. Lastly, the elastic modulus of $\phi 12 \mathrm{~mm}$ longitudinal steel bars is equal to 200 GPA, while the yield and ultimate tensile strengths are 374.3 and $543.2 \mathrm{MPa}$, respectively.

\subsection{FEM Prediction}

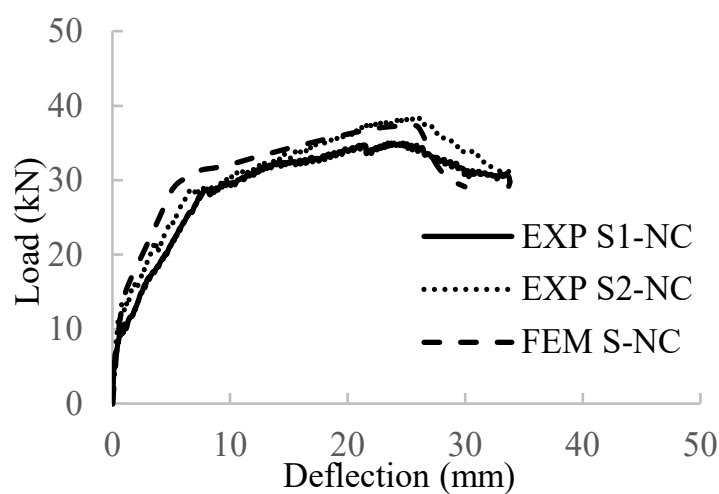

(a)

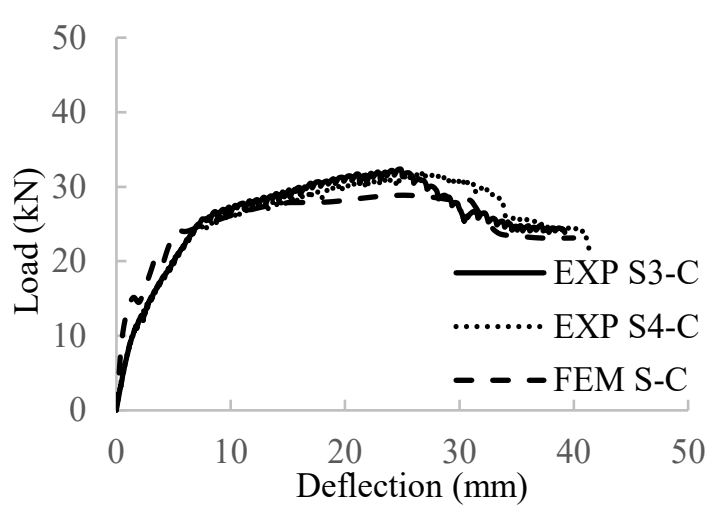

(b)

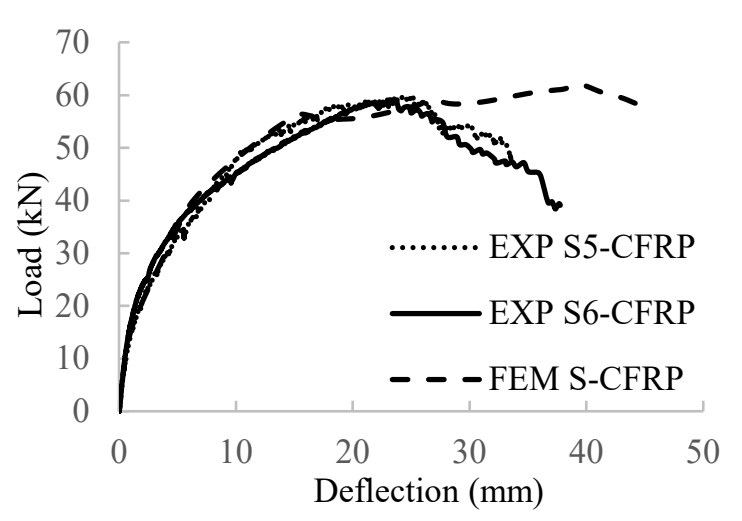

(c)

Fig. 5 EXP and FEA load-deflection curves
The experimental and numerical variations of maximum loading capacity with mid-span deflection under loading points for the tested beams are depicted in Fig. 5. The experimental (EXP) and FEA loading capacity are given in Table 1 . As it can be seen, the stiffness of non-corroded specimens was close up to a load level of $28 \mathrm{kN}$ both in experimental and numerical analysis. Similar nonlinear behavior was extended up to the maximum loading capacity of 38.5 $\mathrm{kN}$ of beam S2-NC and $35.0 \mathrm{kN}$ beam S1-NC in the experiment compared with the value of $35.1 \mathrm{kN}$ in finite element simulation. It shows the good agreement between the two results for the loaddeflection curves as shown in Fig. 5(a).

Table 1 Experimental, FE-predicted maximum load

\begin{tabular}{cccc}
\hline \multirow{2}{*}{$\begin{array}{c}\text { Beam } \\
\text { notation }\end{array}$} & \multicolumn{2}{c}{ Maximum load $(\mathrm{kN})$} & $\begin{array}{c}\text { Deviation } \\
(\%)\end{array}$ \\
\cline { 2 - 3 } & $\begin{array}{c}\text { EXP } \\
\text { (Test) }\end{array}$ & FEA & \\
\hline S1-NC & 35.0 & 35.1 & 0.3 \\
S2-NC & 38.5 & 35.1 & 8.8 \\
S3-C & 32.4 & 28.9 & 10.8 \\
S4-C & 31.9 & 28.9 & 9.4 \\
S5-CFRP & 59.9 & 62.1 & 3.7 \\
S6-CFRP & 59.1 & 62.1 & 5.1 \\
\hline
\end{tabular}

The experimental curves of load - deflection of corroded beams S3-C and S4-C are approximately linear up to crack formation at the corresponding load $25 \mathrm{kN}$. Subsequently, the curves turned nonlinear as a result of stiffness deterioration due to corrosion cracking. The deterioration continued with increased loading until failure occurred with the maximum loading capacity of $32.1 \mathrm{kN}$ on average. Fig. 5(b) clearly demonstrates that there is a very good match between the experimental and FEA load-deflection behavior from initial loading up to beam failure.

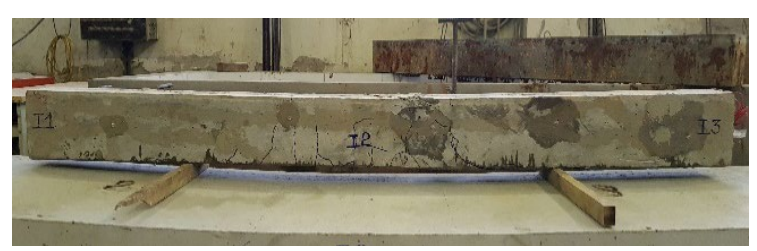

(a)

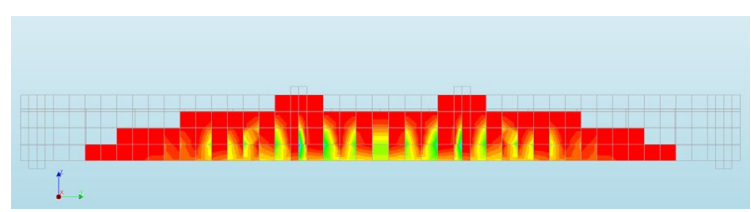

(b)

Fig. 6 Comparison of typical cracking patterns on S5-CFRP beam in (a) experiment and (b) FEA 
Lastly, as the CFRP sheet bonded to the corroded beams C5-CFRP and C6-CFRP, higher yield loads and maximum loads were achieved. For example, the maximum load for beam specimen S5-CFRP was $59.9 \mathrm{kN}$ which approximately doubled the yield load of corroded beams S3-C and S4-C (32.4 kN and 31.9 $\mathrm{kN})$. A similar trend was observed for the maximum capacity of $62.1 \mathrm{kN}$ in the finite element simulation. It is reported in the experiment that the beam suffers from a bonding failure mechanism in the shear span. The crack due to cover separation between concrete and CFRP sheet propagates upwards until meeting the corrosion crack. It continues to travel up to the loading point forming the inclined crack as shown in Fig. 6. On the other hand, the failure mode obtained from $\mathrm{FE}$ analyses is a flexural failure with the crushing of concrete in the compression zone. These differences in failure mode were due to the smeared crack model of concrete used in FEM could not perfectly reflect the influence of localized cracking on laminates. Therefore, it is needed to extend the simulation by using a prescribed discrete crack model and bond-slip model between materials to achieve accuracy in simulating the debonding failure mechanism of strengthened CFRP beams.

\section{FEM PARAMETER ANALYSIS}

In this section, the parametric study on the varying CFRP layers and the CFRP sheet length will be conducted to assess their influence on structural behavior. The FEM of specimen C5-CFRP and C6CFRP are used with the assumption that the same material, geometry described in the experimental section.

\subsection{Effects of CFRP Layers}



Fig. 7 Effet of the CFRP layers on the structural behavior of strengthened corroded beams

Fig. 7 indicates that the stiffness, yield load, the load-carrying capacity of the beam are enhanced with the increase of layers. The load-carrying capacity when using two, three, and five layers improved by $13.1 \%, 25.8 \%$, and $44.8 \%$ in comparison with a single layer. The post-peak response in the load-deflection curve is becoming steeper as the number of FRP layers increased. That behavior indicates the considerable reduction of ductility in beams strengthened with more layers of CFRP sheets. This finding shares the same agreement with the research works on the multiple layers of FRP of RC beams conducted by previous experimental works [21].

\subsection{Effects of CFRP Length}

For the strengthened beams with different CFRP sheet lengths ranging from $1200 \mathrm{~mm}$ to $2000 \mathrm{~mm}$, the development of the load-carrying before cracking is almost the same. In the case of a single layer, the length of the CFRP sheet has a slight effect on the change of load-carrying capacity as illustrated in Fig. 8 . By reducing from $2000 \mathrm{~mm}$ to $1600 \mathrm{~mm}$ length of the strengthening sheet, the load-carrying capacity difference reported is around $3.24 \mathrm{kN}$. There is a more remarkable loss from the $1200 \mathrm{~mm}$ length CFRP sheet ( $800 \mathrm{~mm}$ shorter than the original) which is approximately $12.2 \mathrm{kN}$. As the length of the CFRP sheet decreases, the ductility of the beams decreases as well. This is because the cracking pattern is more evenly distributed over the area where RC beam is bonded with the CFRP sheet. Therefore, the overall sum of all crack widths is reduced and the ductility will be improved.

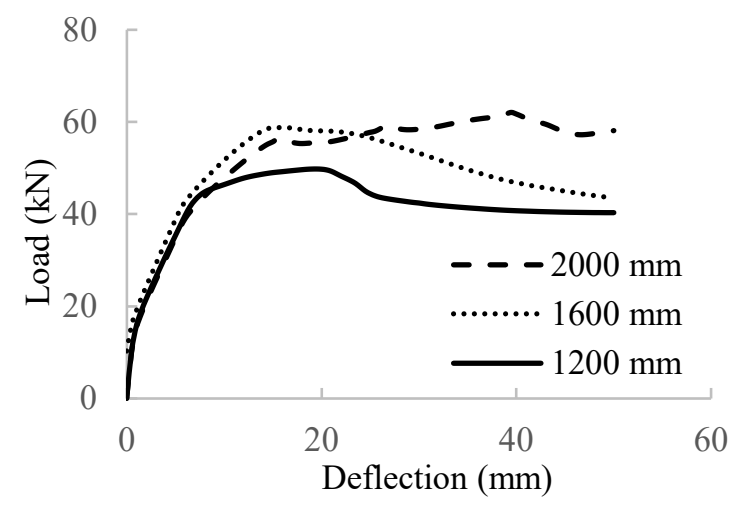

Fig. 8 Effect of CFRP lengths on the structural behavior of strengthened corroded beams

\section{CONCLUSIONS}

The paper contributes to a more understanding of the flexural behavior of RC beams with reinforcement corrosion strengthened with externally bonded CFRP sheets.

A FE model for RC corroded beams flexuralstrengthened with CFRP sheets was successfully validated using published experiments to predict the load-carrying capacity of tested beams with relatively small deviation.

A parametric study is done to examine the capability of the applied FE simulation for many 
variables. It indicated that the predicted flexural strength enhancement was remarkably influenced by the increase of a limited number of CFRP layers while it was smaller affected by the varying CFRP sheet lengths. The strengthened beams behave more ductile when externally bonded with more than one CFRP sheet and the ductility also decreases along with the reduction of sheet length.

\section{ACKNOWLEDGMENTS}

The authors would like to thank Toray International, Inc., Japan for supporting the carbon fiber reinforced polymer materials in this research.

\section{REFERENCES}

[1] ACI 440.2R-17, Guide for the design and construction of externally bonded FRP systems for strengthening concrete structures, ACI Committee 440, 2017.

[2] Ahmadi M., Kheyroddin A. and Kioumarsi M. Prediction models for bond strength of steel reinforcement with consideration of corrosion, Materials Today: Proceedings, 2021.

[3] Yu X., Robuschi S., Fernandez I. and Lundgren K., Numerical assessment of bond-slip relationships for naturally corroded plain reinforcement bars in concrete beams, Engineering Structures, Vol. 239, 2021, 112309.

[4] Zhang Y., Bicici E., Sezen H. and Zheng S., Reinforcement slip model considering corrosion effects, Construction and Building Materials, Vol. 235, 2020, 117348.

[5] Abuodeh O.R., Abdalla J.A. and Hawileh, R.A., Prediction of shear strength and behavior of RC beams strengthened with externally bonded FRP sheets using machine learning techniques, Composite Structures, Vol. 234, 2020, 111698.

[6] Chen W., Pham T.M., Sichembe H., Chen L. and Hao H., Experimental study of flexural behaviour of RC beams strengthened by longitudinal and U-shaped basalt FRP sheet, Composites Part B: Engineering, Vol. 134, 2018, pp.114-126.

[7] Dong J., Wang Q., and Guan Z., Structural behaviour of RC beams with external flexural and flexural-shear strengthening by FRP sheets, Composites Part B: Engineering, Vol. 44, Issue 1, 2013, pp.604-612.

[8] McSwiggan C. and Fam A., Bio-based resins for flexural strengthening of reinforced concrete beams with FRP sheets, Construction and Building Materials, Vol. 131, 2017, pp.618-629.

[9] Godat A., Neale K.W. and Labossière P., Numerical modeling of FRP shear-strengthened reinforced concrete beams, Journal of
Composites for Construction, Vol. 11, Issue 6, 2007, pp.640-649.

[10]Kishi N., Zhang G. and Mikami H., Numerical cracking and debonding analysis of RC beams reinforced with FRP sheet, Journal of Composites for Construction, Vol. 9, Issue 6, 2005, pp.507-514.

[11] Tran H.A., Nguyen H.G. and Nguyen N.T., An experimental study on the flexural strengthening of corroded RC beams using externally CFRP sheet, Journal of Science and Technology in Civil Engineering, Vol. 15, Issue 1V, 2021, pp.1-16 (in Vietnamese).

[12] Bažant Z. P. and Oh B.H., Crack band theory for fracture of concrete, Materials and Structures, Vol. 16, 1983, pp.155-177.

[13] Maekawa K., Pimanmas A. and Okamura H., Nonlinear mechanics of reinforced concrete, Spon Press, London, 2003.

[14]DIANA 10.3 User's manual, TNO Building and Construction Research, Delft, 2019.

[15] Nakamura H. and Higai T., Compressive fracture energy and fracture zone length of concrete, In: Modelling of inelastic behaviour of RC structures under seismic loads, Shing P. and Tanabe T-A., Ed., American Society of Civil Engineers, 2001, pp.471-487.

[16] Coronelli D. and Gambarova P., Structural assessment of corroded reinforced concrete beams: modeling guidelines, Journal of Structural Engineering, Vol. 130, Issue 8, 2004, pp.1214-1224.

[17] Stewart M.G., Mechanical behaviour of pitting corrosion of flexural and shear reinforcement and its effect on structural reliability of corroding RC beams, Structural Safety, Vol. 31, Issue 1, 2009, pp.19-30.

[18] Chen E., Berrocal C.G., Fernandez I., Löfgren I. and Lundgren K., Assessment of the mechanical behaviour of reinforcement bars with localised pitting corrosion by Digital Image Correlation, Engineering Structures, Vol. 219, 2020, 110936.

[19]Fib. CEB-FIP model code 1990. London: Thomas Telford Services Ltd; 1993.

[20] Tørlen A. and Horrigmoe G., Modelling of bond between reinforcement and concrete for deteriorated and repaired beams, Report No. NTAS A98034, NORUT Technology, 1998, Narvik, Norway. (in Norwegian).

[21] Bsisu, K., Sargand, S., and Ball, R., The effect of width, multiple layers and strength of FRP sheets on strength and ductility of strengthened reinforced concrete beams in flexure, Jordan Journal of Civil Engineering, Vol. 9, Issue 1, 2015, pp.33-42.

Copyright (C) Int. J. of GEOMATE All rights reserved, including making copies unless permission is obtained from the copyright proprietors. 